\title{
Student Active Learning Tool for Producing Open Resources in Microwave Engineering Education
}

\author{
https://doi.org/10.3991/ijep.v9i4.10903
}

\author{
Abdallah Al-Zoubi \\ Princess Sumaya University for Technology, Amman, Jordan \\ zoubi@psut.edu.jo
}

\begin{abstract}
Producing Open educational resources (OER) in engineering education utilizing the concept of project-based learning enables students to train and gain knowledge and skills and contribute to the learning process of other learners worldwide. The advantage of this new peer-to-peer approach is that it allows students to learn from their fellow students in an open domain, and hence provide a vantage point in the transformation of traditional classroom pedagogies into a new educational approach embodied in student-centred learning. A long-term experiment has been conducted at Princess Sumaya University for Technology to introduce the concept of project based learning in teaching a microwave engineering course at the undergraduate level and hence produce OER material to allow students over the globe to utilize in their learning process.
\end{abstract}

Keywords-Microwave engineering education, open educational resources, projectbased learning.

\section{Introduction}

Project-based learning has actually become a necessity and a requirement in teaching certain undergraduate engineering courses [1-3]. Such courses is "microwave engineering" which requires instructors to devote a substantial amount of time to equip students with the necessary knowledge and skills to design circuits and systems using modern microstripline technology [4-6]. The course relies heavily on the use of graphical tools such as the Smith chart to carry out calculations of impedance and reflection coefficient associated with the standing-wave pattern created by multiple reflections of the waves on the transmission line. In addition, the complete design of a microwave amplifier, which occupies a considerable portion of the course, can be completely undertaken using the Smith chart [7-8]. This requires calculation of several variables, based on the scattering parameters of the amplifier, and to follow rigorous procedures that lead to the ultimate goal of designing input and output matching networks [9]. The procedures include plotting on the Smith chart a number of stability, gain and noise figure circles which consequently allow the student to visually select a combination of appropriate conditions and design requirements. The process is however tedious, time consuming and absorbs most of students' efforts and professor alike. Modern technology-enhanced learning tools may constitute an appropriate solution to teaching such a complex and advanced course [10-11] and turn it into an 
exciting and challenging endeavour by engaging students in the actual design process through project assignments that are heavily based on technology-enhanced learning tools, where some eventually become their own design.

A new interactive teaching approach was introduced in recent years in teaching microwave engineering at Princess Sumaya University for Technology. The approach is characterised by adopting procedures which enable the instructor to conduct a classes using software tools which facilitates making appropriate drawings and graphics to simply a rather lengthy, cumbersome and redundant calculations and procedures [9]. A series of circles which represent the microwave amplifier stability, gain and noise figure which are plotted on a software platform called KETAB, optimum design solution selected and consequently impedance matching circuits are identified and drawn.

In this paper, the design and utilization of a calculator to compute and plot various parameters required in the design of microwave amplifiers is described. The calculator is based on a user-friendly Matlab programming designed by students to provide a visual display of constant, operating and available power gain circles as well as noise figure circles, drawn in the Smith chart. The procedure is further supported by the implementation of the software platform for detailed elaboration of the design process allowing students to record and post online videos into YouTube, as part of a projectbased learning exercise. The videos produced constitute a form of an open educational resource which is made available for fellow students worldwide to access and utilize in corresponding courses of the study programmes.

\section{Microwave Engineering Curriculum}

Microwave Engineering is a course that introduces students to microwave systems, components and devices and partly analysis, design, and performance of passive and active elements such as transmission lines, matching networks, and microwave amplifiers, particularly their design process. The course develops an understanding of the microwave circuit analysis technique, mathematical basis, and particularly their application to the solution of real-world problems as it exposes students to circuit design tools used in microwave engineering. The design of microwave transistor amplifiers using S-parameters combine active elements with passive transmission line circuits to provide functions critical to microwave systems and instruments. The design techniques used for of BJT and FET amplifiers employ the full range of concepts that developed in many studies of microwave transmission lines, two-port networks and Smith chart drawings. The Smith chart, created by Philip Smith in 1939, is a simple transformation of the equation that relates the reflection coefficient to the load impedance terminating the transmission line. Simple mathematical manipulations show that this transformation results in a series of resistance or r-circles and reactive or $\mathrm{x}$ circles, where $\mathrm{r}$ and $\mathrm{x}$ are the normalized resistance and reactance. The Smith chart is actually a useful graphical aid to the circuit designer that has been used extensively over decades for the design of high-frequency transistor circuits employing strip transmission lines on high-frequency substrate materials. This graphical method is particularly effective for the design of microwave transistor amplifier which facilitates 
the demarcation of stable and unstable regions of operation on the chart, thereby allowing the proper choice of gain, noise-figure and VSWR and hence input and output matching networks for the desired mode of operation [9].In the design of a single stage microwave amplifier with certain S-parameters, it is usually assumed that the transistor is driven by a source with $Z_{S}$ impedance, and that its output is connected to a load $Z_{L}$, as shown in the schematic of Fig. (1).

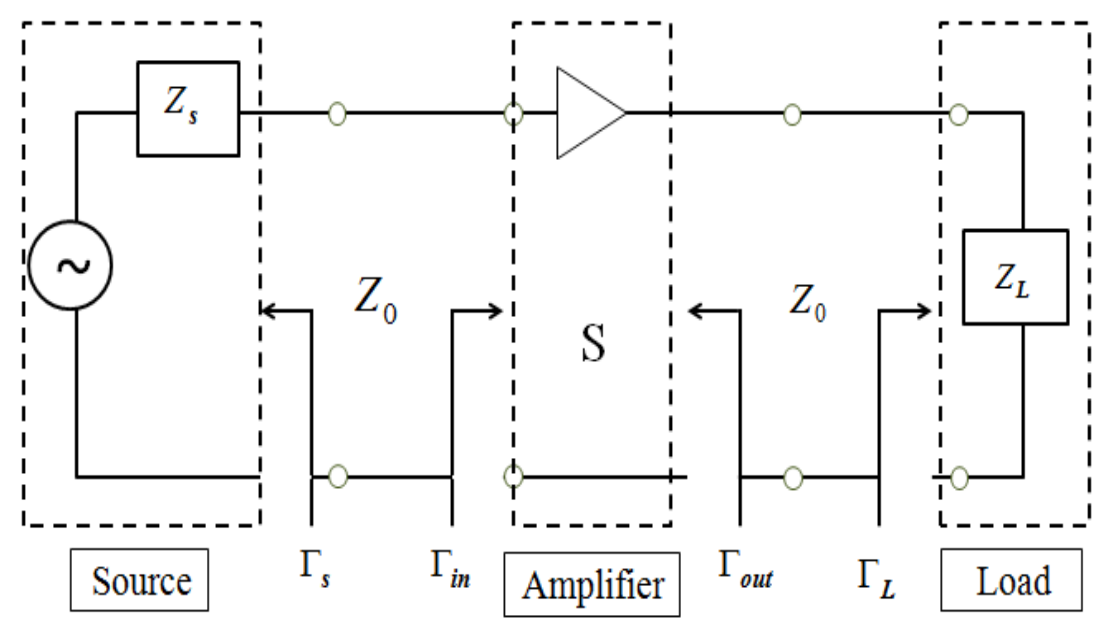

Fig. 1. Schematic of a typical single stage transistor amplifier.

Using the appropriate signal flow diagram and applying Mason's rule to obtain the output/input transfer function; the transducer power gain $G_{t}$ can be obtained [9]:

$$
G_{t}=\frac{\left(1-\left|\Gamma_{S}\right|^{2}\right)\left|S_{21}\right|^{2}\left(1-\left|\Gamma_{L}\right|^{2}\right)}{\mid\left(\left.\left(1-S_{11} \Gamma_{S}\right)\left(1-S_{22} \Gamma_{L}\right)\left(1-S_{21} S_{12} \Gamma_{S} \Gamma_{L}\right)\right|^{2}\right.}
$$

Where $\Gamma_{S}$ and $\Gamma_{L}$ are the source and load reflection coefficients respectively. The available power gain $G_{a}$, defined as the ratio of the power available from network to that delivered to the load, is given by [9]:

$$
G_{a}=\frac{1-\left|\Gamma_{S}\right|^{2}}{\left|1-S_{11} \Gamma_{S}\right|^{2}}\left|S_{21}\right|^{2} \frac{1}{\left|1-\Gamma_{\text {OUT }}\right|^{2}}
$$

while the operating power gain $G_{p}$, defined as the ratio of the power available from source to that delivered to the network:

$$
G_{p}=\frac{1}{1-\left|\Gamma_{I N}\right|^{2}}\left|S_{21}\right|^{2} \frac{1-\left|\Gamma_{L}\right|^{2}}{\left|1-S_{22} \Gamma_{L}\right|^{2}}
$$

where the reflection coefficients at the input and output are described by:

$$
\Gamma_{I N}=S_{11}+\frac{S_{12} S_{21} \Gamma_{L}}{1-S_{22} \Gamma_{L}}
$$




$$
\Gamma_{\text {OUT }}=S_{22}+\frac{S_{12} S_{21} \Gamma_{S}}{1-S_{11} \Gamma_{S}}
$$

The noise performance of the amplifier is also investigated in a similar manner and circles for certain values of noise figure $F_{i}$ are calculated and plotted on the Smith chart such that [9]:

$$
\begin{gathered}
F_{i}=F_{\text {min }}+\frac{4 r_{n}\left|\Gamma_{S}-\Gamma_{0}\right|}{\left(1-\left|\Gamma_{S}\right|^{2}\right)\left(1+\left|\Gamma_{0}\right|^{2}\right)} \\
N_{i}=\frac{F_{i}-F_{\text {min }}}{4 r_{n}}\left|1+\Gamma_{0}\right|^{2}
\end{gathered}
$$

where $F_{\min }$ is the minimum noise figure of the transistor, $\Gamma_{o}$ is the noise reflection coefficient and $r_{n}$ is the normalized noise resistance.

Generally, a simple small-signal microwave amplifier design procedure begins with choosing suitable bias conditions for gain, linearity, noise, etc. The biasing parameters will then set the small signal S-parameters of the transistor. The next step is to determine the delta factor $\Delta$ and stability factors $K$ as well as the values of radius and centre of the stability circles at the input and output and to plot them on the Smith chart to see if the amplifier is unconditionally stable or potentially unstable. Consequently, various circles are plotted, with radii and centres as shown in table (1), according to a required design criterion such as gain, noise figure and VSWR.

Table 1. Centres and radii of amplifier design circles.

\begin{tabular}{|c|c|c|}
\hline Circle & Centre & Radius \\
\hline Stability & $C_{S}=S_{11}-\Delta S_{22}^{*}$ & $r_{S}=\frac{\left|S_{12} S_{21}\right|}{\left.|| S_{11}\right|^{2}-|\Delta|^{2} \mid}$ \\
\hline Constant Gain & $d_{\mathrm{s}}=\frac{g_{n s}\left|S_{I I}\right|}{\left.|1-| S_{I 1}\right|^{2}\left(1-g_{n s}\right) \mid}$ & $r_{s}=\frac{\sqrt{1-g_{n s}}\left(1-\left|S_{I I}\right|^{2} \mid\right.}{1-\left|S_{11}\right|^{2}\left(1-g_{n s}\right)}$ \\
\hline Operating Power Gain & $C_{p}=\frac{g_{p} C_{2}^{*}}{\left.\left|1+g_{p}\right|\left|S_{22}\right|^{2}-|\Delta|^{2}\right) \mid}$ & $r_{p}=\frac{\left(1-2 k\left|\mathrm{~S}_{12} \mathrm{~S}_{21}\right| g_{p}+\left|S_{12} S_{21}\right|^{2} g_{p}^{2}\right)^{\frac{1}{2}}}{\mid 1+g_{p}\left(\left|S_{22}\right|^{2}-|\Delta|^{2}||^{2}\right.}$ \\
\hline Available Power Gain & $C_{a}=\frac{\mathrm{g}_{\mathrm{p}} C_{1}^{*}}{\left.\left|1+\mathrm{g}_{\mathrm{p}}\right|\left|\mathrm{S}_{11}\right|^{2}-|\Delta|^{2}\right) \mid}$ & $r_{a}=\frac{\left(1-2 k\left|S_{12} S_{21}\right| g_{p}+\left|S_{12} S_{21}\right|^{2} g_{p}^{2}\right)^{\frac{1}{2}}}{\mid 1+g_{p}\left(\left|S_{11}\right|^{2}-\left.|\Delta|^{2}\right|^{2}\right.}$ \\
\hline Noise Figure & $\mathrm{C}_{\mathrm{r} i}=\frac{\Gamma_{0}}{1+N_{i}}$ & $\mathrm{r}_{r i}=\frac{1}{1+N_{i}}\left[N_{i}^{2}+N_{i}\left(1-\left|\Gamma_{0}\right|^{2}\right)\right]^{\frac{1}{2}}$ \\
\hline
\end{tabular}

Once done, matching networks $(\mathrm{MN})$ at the input and output are selected to transform the source and load to impedances that will provide the required gain, noise figure and voltage standing wave ratio (VSWR) as shown in Fig. (2). The matching networks usually consist of a combination of series or parallel LC components of several configurations. 


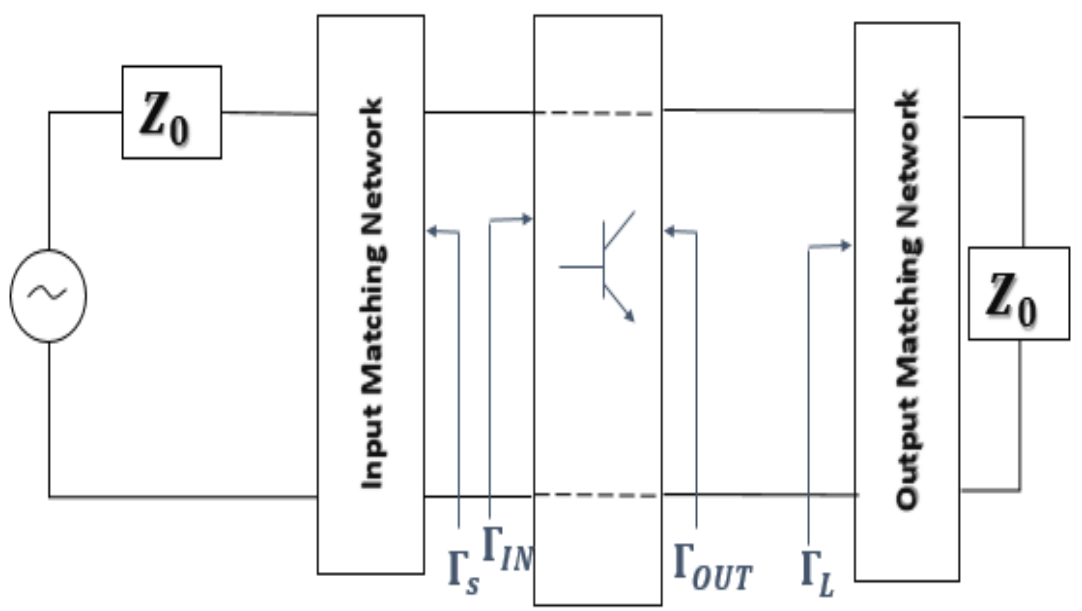

Fig. 2. Schematic of a typical single stage transistor amplifier.

\section{Amplifier's Parameters Calculation}

A Matlab programme was designed by students themselves over a number of semesters to compute all possible parameters that may enter in the design process of microwave amplifiers such as transducer, operating and available power gain circles, stability, noise figure, VSWR and reflection coefficients. The comprehensive calculator has in fact played a vital role in facilitating the plotting process of the various amplifier circles since students needed to draw as many circles possible in the Smith chart for one single design variable in order to arrive at the optimum solution and hence decide on appropriate matching networks. The programme begins by requesting insertion of the S-parameters of the transistor employed in the amplifier as an input, in addition to $\Gamma_{S}$ and $\Gamma_{L}$ if required. Computed basic data such as delta factor $\Delta$, stability coefficient $\mathrm{K}$, unilateral figure of merit $\mathrm{U}, \Gamma_{I N}$ and $\Gamma_{\text {OUT }}$ may then be displayed on separate new windows, and several transducer gain values such as maximum, matched and unilateral gains are calculated and exhibited on further windows. The student may also obtain the parameters of the input and output stability circles including the distance of their centres from the origin of the Smith chart and the angles, together with the radius of each circle, as depicted in Fig. (3). 


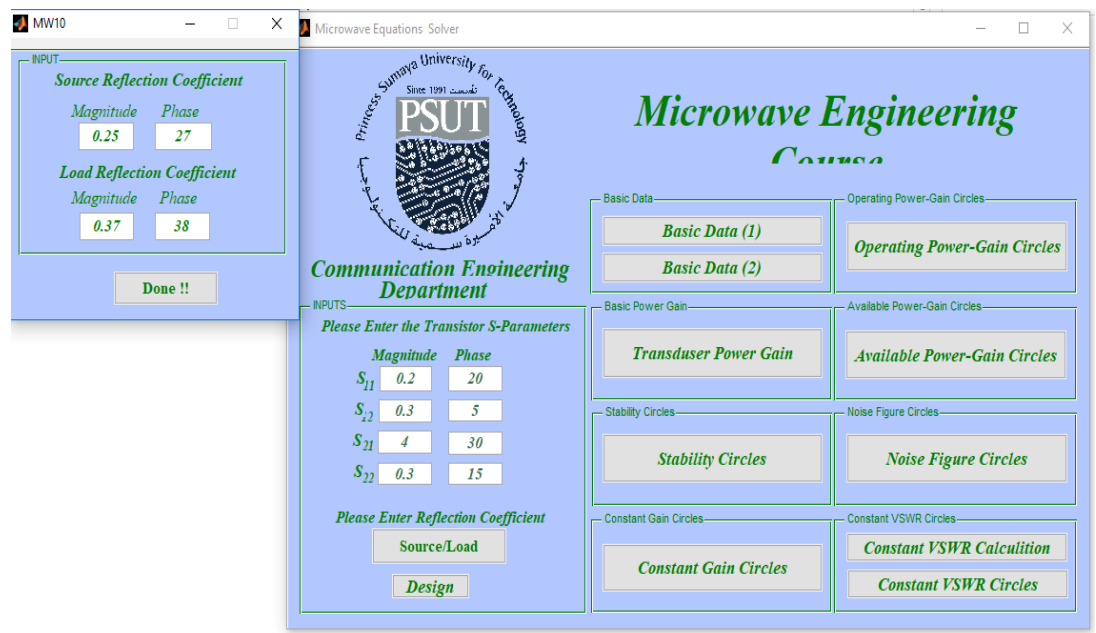

Fig. 3. MATLAB calculator of various parameters to facilitate amplifier design.

Students then proceed with the calculations by selecting the desired circles to draw. Usually a set of circles are drawn for each required gain or noise figure in order to allow for best design criterion. The magnitude and angle of the center of each gain circle and its radius are calculated, as shown in Fig. (4), and tabulated accordingly. Once the required computations are made, students move to the next stage of the design process utilizing KETAB interactive platform for drawing the required circles on the Smith chart.

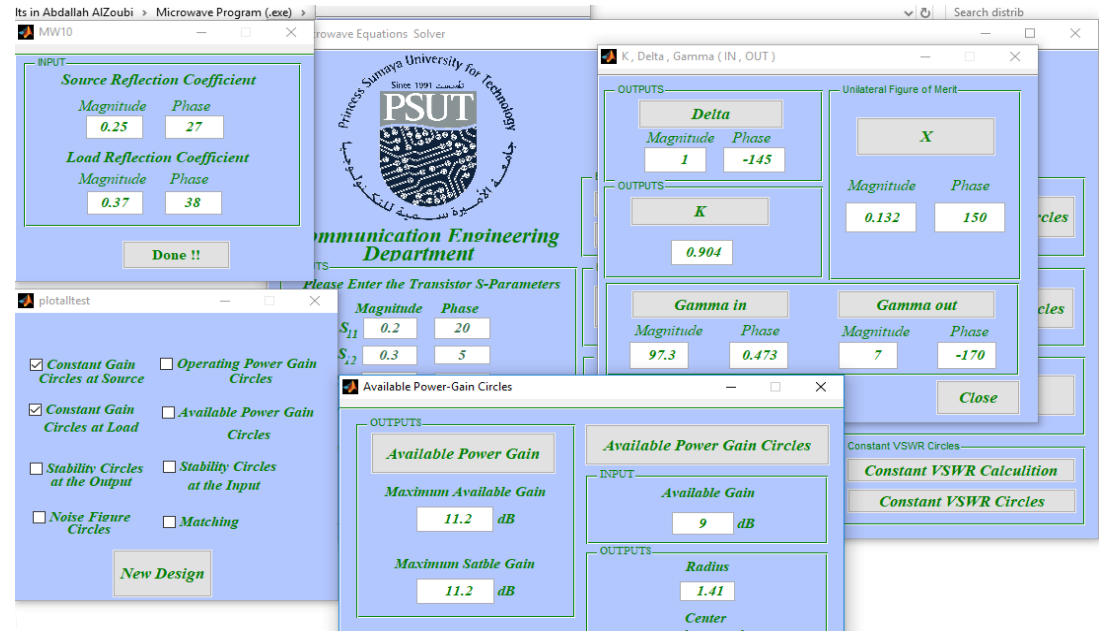

Fig. 4. Calculator outputs for given input parameters.

The programme was improved further to draw a blank Smith chart with coloured impedance and admittance planes that appears next to the input windows. The pro- 
gramme waits for the user to insert the required gain in $\mathrm{dB}$ and automatically draws the circle on the chart. The user has the options to clear the Smith chart or create a new circle over the previous one once the value of the new gain is entered, and the process is repeated until a set of gain or noise figure circles is obtained as shown in Fig. (5). The process is in fact duplicated for constant gains at the input and output, available power gain, operating power gain and noise figure. After selecting the desired circles with the inputs inserted individually at the first stages, the final output will appear in the blank Smith chart in the design phase.

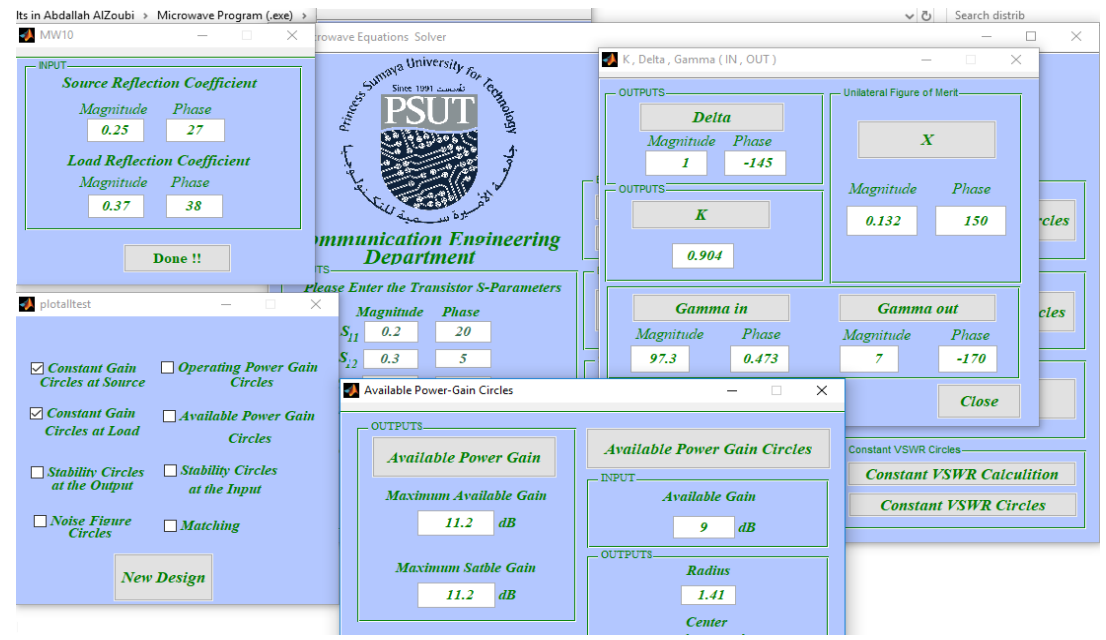

Fig. 5. Calculator outputs for given input parameters.

\section{$4 \quad$ Interactive Software Platform}

KETAB is a self-learning platform which aims to improve the educational experience of learners and guide social networks into positive and distinguished ways. It truly endorses creativity and talent to make education and learning an exciting and enjoyable endeavour while taking into considerations the individual differences through interactive means. The platform actually allows instructors to prepare engaging lessons and presentations on all digital devices with full activities that grab student's attention and make them eager to learn with a sense of responsibility and recreation.In fact, the platform houses web applications that enable the user to search and download content without leaving the lesson. For example, pen, camera and screen recorders are a number of efficient tools that make it convenient for the teacher to prepare and record short lessons where the entire concept is explained, recorder and saved without exhausting the memory of the PC or affecting its performance. Lessons may be published on the web directly. In addition, the platform contains educational applications that include transforming data into charts allowing the audience to perceive the conveyed message at a glance, insert equations or formulae in order to widen the range of taught subjects, use of Cartesian plane, word trace tools to enhance 
students' handwriting ability while writing on sequenced dotted guidelines, and quiz builder as a tool for assessment of strengths and weaknesses of students understanding and comprehension.

The platform embraces other key features such as view modes to navigate between various operational modes, capture tools to record, pool of mathematical objects and symbols, measurement tools to perform geometric operations such as measuring angles using protractor and drawing circles using compass and rulers, text tools to create and format a text, object tools to align, snap to grid grouping, pen tools, utilities such as timer, stop watch and magnifier, page layout, header and footer. In addition, the platform enables the user to import and export documents from sources MS Powerpoint, MS Word, PDF, image, HTML, package and zip file. Further features the platform enjoys are on-demand help to enable the user to obtain information about the studio functionalities, Web applications to navigate across other educational websites smoothly and directly, text to speech conversion which enables the user to listen to typed text being read back with two options, one reading the whole text or single word upon mouse click. The last important capabilities of the platform are the pen recorder which facilitates recording all user activities smoothly, including both pen and mouse events, for later replay, and the library which may be utilized for preparing and illustrating lessons, searching, opening or adding new objects to the studio.

The platform has been effectively utilised in the delivery of the microwave engineering class at the Communication Engineering Department of Princess Sumaya University for Technology since 2011. KETAB Studio has actually been created by two of the university graduates and is currently being implemented in classes at schools and universities in several countries. An early example of the use of the platform to illustrate how a problem is solved on the Smith chart is shown in Fig. (6). In the example, the Smith chart in PDF format is imported into a new page, various tools such as the compass, ruler and text are used in the same way as in traditional paper charts to plot the required circles and determine the required outputs. The entire process is recorded using either the built-in recording tool or Camtasia studio software application to create videos and produce an educational resource with embedded voice of instructor or student. This particular example has reached over 30000 views on YouTube and has apparently been of great help to many students all over the world. Many other similar examples on amplifier design procedures have been prepared by students over the years as part of a project-based learning initiative, youtube.com $/$ watch? $v=$ KcliUp_HGj4\&t $=741$ s. 


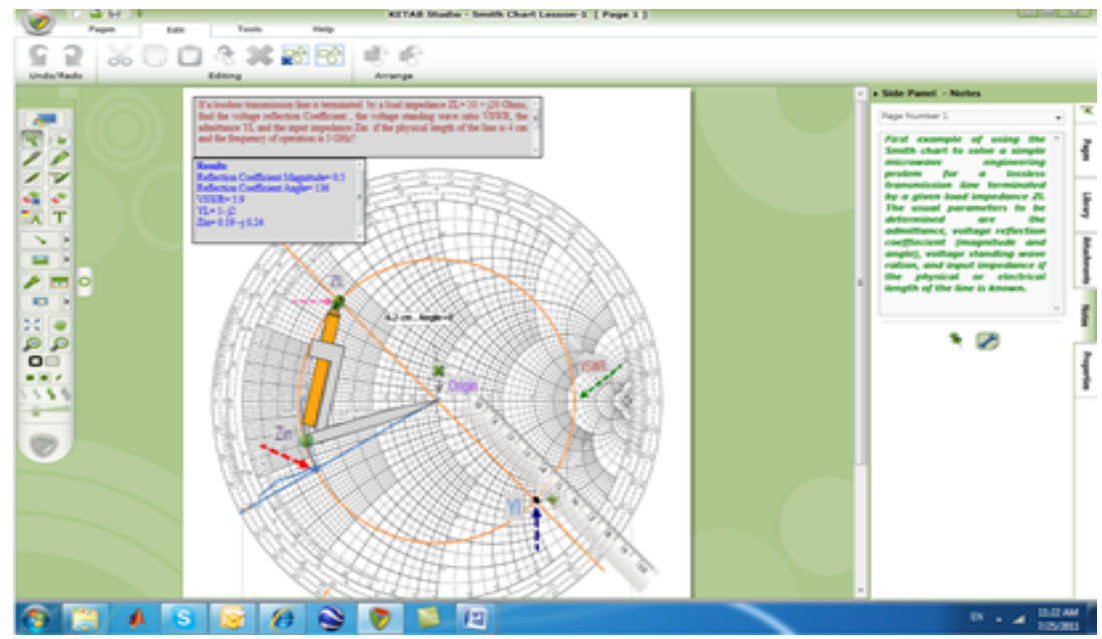

Fig. 6. A worked engineering example using the Smith chart on the KETAB platform

\section{Discussion}

During the past several semesters, students were assigned many tasks to solve microwave amplifier design problems. Once they cover basic microwave amplifier design and matching network techniques, full examples on impedance matching as well as amplifier stability, gain, noise and VSWR measurements are presented using inthe-class smart board. Students are then equipped with the platform and parameters' calculator to conduct their own training while following the professor in the class. After solving several examples and mastering drawings on the Smith chart utilizing the platform, students were formed in groups and assigned tasks of various complexity, such as the example below in Fig. (7), on drawing constant gain circles at the input and output of the amplifier for given transistor S-parameters. The tasks included experimenting on following procedures, determining and drawing a multitude of variables required in the design process of microwave amplifiers until students are able to design a complete circuit of the amplifier with its matching networks at the input and output for a given gain, noise figure and VSWR values following specific criteria, hence providing a comprehensive design tool. Students have participated actively and regularly in this interactive classroom and used it effectively to produce their own educational videos that were posted online on YouTube. New students would consequently utilize such a pool of educational resources to enhance their understanding of the course with little interference from the instructor or teaching assistants. The pool has piled up and accumulated with time, and a diversity of solved examples and designs offer the opportunity to students to examine or even entertain at their own pace in a conducive and provocative environment.

The calculator not only computes all possible parameters that may enter in the design process, but also contributes in plotting certain graphics, particularly circles and circuit components. It has been further equipped with the ability to generate all re- 
quired circles to enable students to benchmark and check their solutions as shown in the example of Fig. (8) in which stability circles at the input and output are shown in addition to noise figure and available power gain circles. Once the student decides on the amount of gain required by identifying its corresponding circle, then choosing the appropriate noise figure and locating its circle, the intersection hence gives the operating point and the value of the reflection coefficient at the input. Moving from the intersection point to the origin of the Smith chart thus yields the matching network at the input, assuming a match at the out output. The movement may take several paths on constant/unity impedance circle and consequently on unity/constant admittance circle or vice versa to obtain the LC matching network.

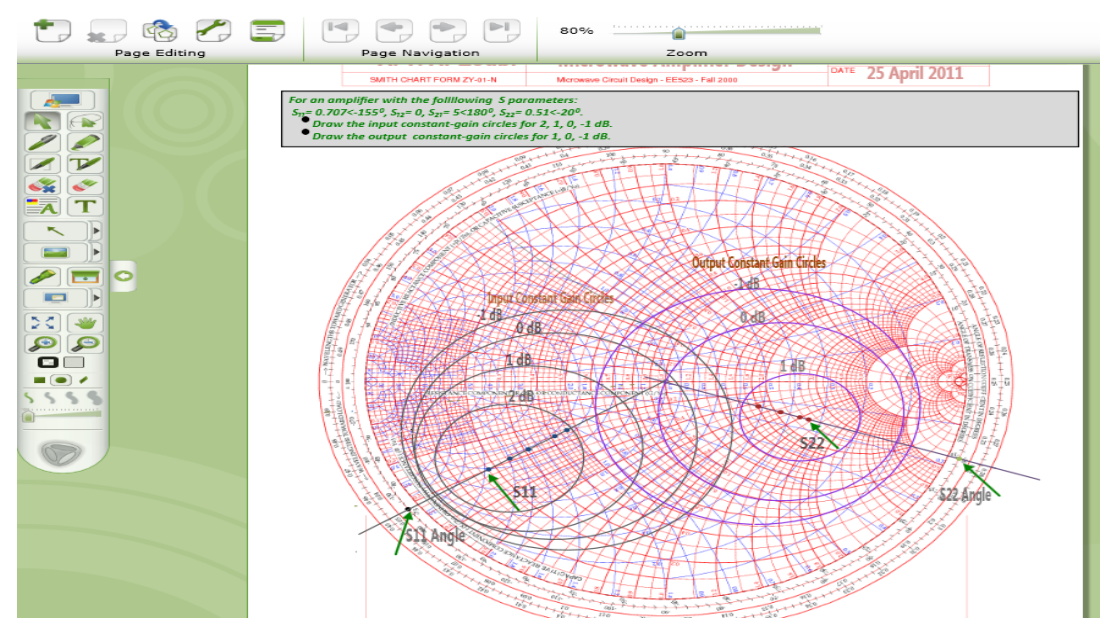

Fig. 7. Several constant-gain circles at the input and output.

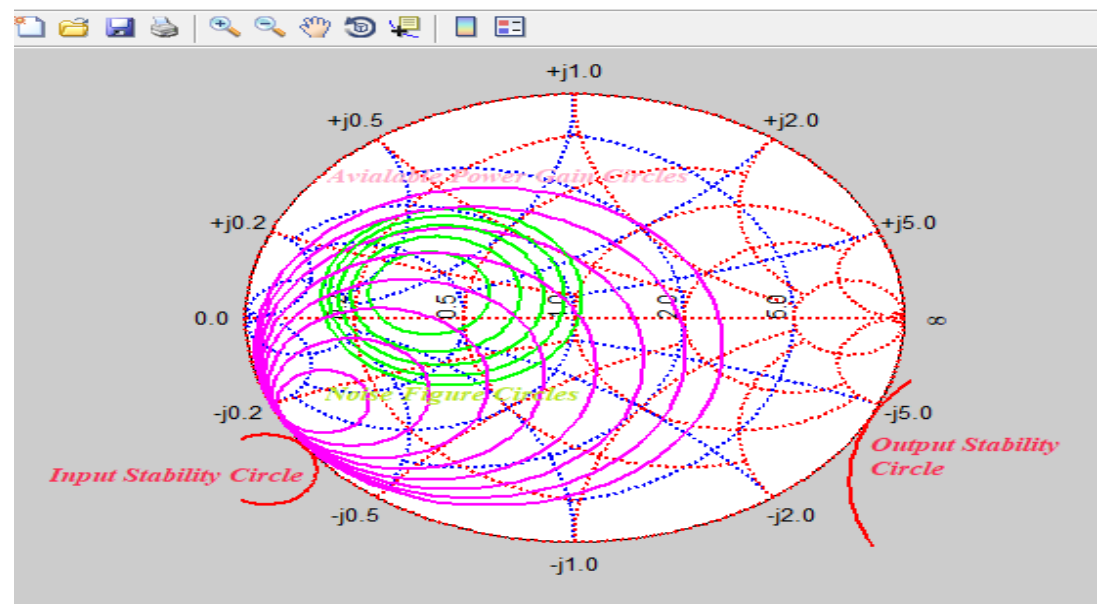

Fig. 8. Complete example of designing matching networks of a microwave amplifier as produced by the calculator. 
Once students make sure of the design, the process is recorded, with a step by step voice instructions, and then posted online in the university YOUTUBE channel. Many exampleshave been produced over several semester on determine matching networks, stability, constant gain, operating power and available power gain as well as noise figure, and consequently on a complete design example.

According to Accreditation Board for Engineering and Technology (ABET) accreditation, engineering programs must demonstrate and document student outcomes that prepare graduates to attain the program educational objectives as listed at https://www.abet.org/accreditation/accreditation-criteria/criteria-for-accrediting-engineeringprograms-2016-2017/.The learning outcomes are listed below:

- An ability to apply knowledge of mathematics, science, and engineering.

- An ability to design and conduct experiments, as well as to analyze and interpret data.

- An ability to design a system, component, or process to meet desired needs within realistic constraints such as economic, environmental, social, political, ethical, health and safety, manufacturability, and sustainability.

- An ability to function on multidisciplinary teams.

- An ability to identify, formulate, and solve engineering problems.

- An understanding of professional and ethical responsibility.

- An ability to communicate effectively.

- The broad education necessary to understand the impact of engineering solutions in a global, economic, environmental, and societal context.

- Recognition of the need for, and an ability to engage in life-long learning.

- A knowledge of contemporary issues.

- An ability to use the techniques, skills, and modern engineering tools necessary for engineering practice.

For the microwave engineering course, the course learning outcomes were designed such that upon its completion, students will have had an opportunity to learn the following course outcomes which are mapped to the ABET programme learning outcomes and Blooms taxonomy as indicated in the consecutive brackets:

- Demonstrate theoretical knowledge and concepts of microwave devices and components as applied to communication systems. (a) (K)

- Utilize Smith Chart in solving microwave engineering problems. (c) (S)

- Design microwave circuits using analytical and graphical procedures. (c, k) (AR)

- Design an amplifier integrating the components of microwave engineering system. $(\mathrm{c}, \mathrm{k})(\mathrm{RC})$

- Integrate the principles of microwave measurement techniques and instrumentation in validating designs. (c, $\mathrm{k})(\mathrm{SD})$

A questionnaire for "Course Assessment by Students" which measures the intended outcomes of the course was the main assessment tool at the end of each semester. In the questionnaire, the level of achievement of outcomes was measured using a scale 1 to 5 , where 1 corresponds to poor achievement, and 5 to strong achievement. The 
results for one semester for the five learning outcomes of the course (a, c, e, g, k) are shown in Fig. (9). An average of 4.72 out of 5 was obtained.

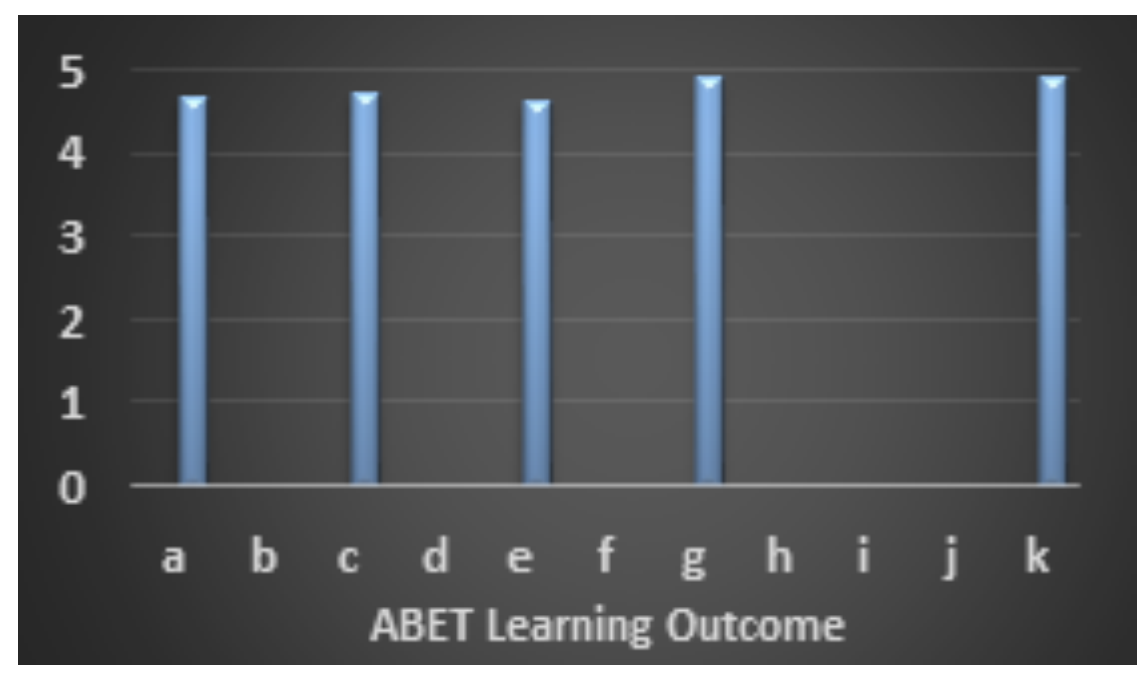

Fig. 9. Results of course assessment by students.

Course Assessment by Faculty (CAF) is another important instrument to measure the performance of students. One performance indicator was set to evaluate attainment of student and to measure the targeted ABET outcome (c) which was set at the beginning of the course so as to empower students with "an ability to design a system, component, or process to meet desired needs within realistic constraints such as economic, environmental, social, political, ethical, health and safety, manufacturability, and sustainability". The specific outcome identified in this course was to "design a microwave amplifier with a given gain, noise figure and VSWR to meet given specifications at certain frequencies". The indicator reflected in a number of questions in quizzes, homeworks and exams. The Department of Communications Engineering considers the delivery of the course adequate if the average answers of all questions is above 3.125 out of 5 or approximately $65 \%$, which is followed as a rule in regards to measuring the performance indicator of the students to reach a developing level or above. Details of the classification of the evaluation criteria are shown in table (2) and the level of achievements are shown in Fig. (10). Most of the students were able to design the microwave amplifier and to follow proper techniques and processes. All, but one student who dropped the course, were above the developing level. Overall, the performance of the students on "outcome c" was good. Only 11 students attended the final exam in this example course. 


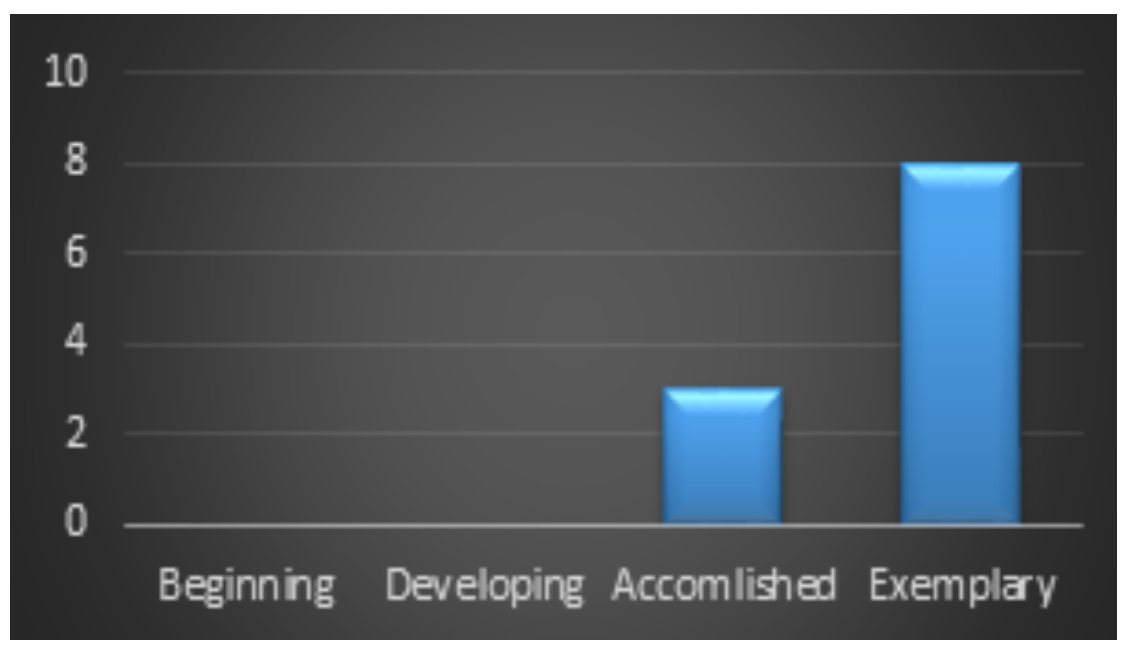

Fig. 10.Results of evaluation of students according to achieving the target key performance indicator

Table 2. Criteria of Evaluation of Students According to Achieving Key Performance Indicator

\begin{tabular}{|c|c|c|c|c|}
\hline $\begin{array}{l}\text { Performance Indi- } \\
\text { cator }\end{array}$ & $\begin{array}{c}\text { Beginning (0-2) } \\
\text { Points }\end{array}$ & $\begin{array}{c}\text { Developing (2-3) } \\
\text { Points } \\
\end{array}$ & $\begin{array}{c}\text { Accomplished (3-4) } \\
\text { Points }\end{array}$ & $\begin{array}{c}\text { Exemplary (4-5) } \\
\text { Points } \\
\end{array}$ \\
\hline $\begin{array}{l}\text { Design a micro- } \\
\text { wave amplifier } \\
\text { with a given gain, } \\
\text { noise figure and } \\
\text { VSWR to meet } \\
\text { given specifica- } \\
\text { tions at certain } \\
\text { frequencies. }\end{array}$ & $\begin{array}{l}\text { Student failed to } \\
\text { calculate the pa- } \\
\text { rameters of the } \\
\text { amplifier using the } \\
\text { microwave calcu- } \\
\text { lator. }\end{array}$ & $\begin{array}{l}\text { Student managed } \\
\text { to calculate the } \\
\text { parameters of the } \\
\text { amplifier but } \\
\text { failed to draw } \\
\text { stability, gain, } \\
\text { noise figure cir- } \\
\text { cles, using } \\
\text { KETAB software } \\
\text { platform. }\end{array}$ & $\begin{array}{l}\text { Student was able } \\
\text { to correctly calcu- } \\
\text { late amplifier } \\
\text { parameters includ- } \\
\text { ing stability, gain } \\
\text { and noise figure, } \\
\text { properly identified } \\
\text { appropriate oper- } \\
\text { ating point and } \\
\text { measured the } \\
\text { source reflection } \\
\text { coefficient, its } \\
\text { corresponding } \\
\text { VSWR. }\end{array}$ & $\begin{array}{l}\text { Student was able } \\
\text { to correctly calcu- } \\
\text { late the amplifier } \\
\text { parameters includ- } \\
\text { ing stability, gain } \\
\text { and noise figure, } \\
\text { properly identified } \\
\text { an appropriate } \\
\text { operating point } \\
\text { and measured the } \\
\text { source reflection } \\
\text { coefficient, its } \\
\text { corresponding } \\
\text { VSWR, and final- } \\
\text { ly designed the } \\
\text { matching network. }\end{array}$ \\
\hline
\end{tabular}

The proposed student active learning tool has been praised by fellow academic staff teaching other engineering courses in various disciplines. In addition, the leadership of the institution has embraced the proposed mechanism due to the advantages and the added value it brings as well as the benefits and fruits it produces, particularly in safeguarding international standards, norms and requirements mandated by ABET accreditation rules that must be maintained in order to preserve and protect the recognition received by this reputed and prestigious world-class accreditation body. The main advantage of the proposed approach was it power to make all educational re- 
sources available to students worldwide who can access and harness the knowledge gained in similar courses, such as electromagnetism, antennas or microwave engineering, at their own institutions, or even for curiosity and fun to that matter.

\section{Conclusion}

A new student peer-to-peer educational approach was proposed for teaching a microwave engineering course at the undergraduate level. The simple concept was instituted on project-based learning which encouraged students to consequently producing online videos posted in open source YOUTUBE channels. A software platform was conveniently harnessed in providing visual means of the graphical solution used in the microwave amplifier design process and a programme designed by students to calculate various parameters required in the design of microwave amplifiers and basically compute the radii and centres of stability, constant, operating and available gain as well as noise figure circles, was utilized. Several open educational resources were consequently produced and used for teaching and learning purposes to provide an opportunity for everyone to share, use, and reuse. Producing such open educational resources and material may in fact enable fellow students worldwide to train, acquire knowledge and skills and hence contribute to their learning process in the microwave engineering course.

The proposed peer-to-peer approach provided a vantage point in the transformation of traditional microwave engineering classroom pedagogies into a new educational approach embodied in student-centred learning and may be easily employed in any curriculum or university course which bear similar resemblance to the content and pedagogy of the course under consideration and consequently implemented in flipped classrooms and student-centred and life-long learning.

\section{Acknowledgement}

The author would like to thank Princess Sumaya University for Technology for the financial support provided during the sabbatical year.

\section{References}

[1] Moundridou, M., Zalavra, E., Papanikolaou, K. and Tripiniotis, A. (2019). Collaboratively developing open educational resources for engineering educators in SlideWiki, International Journal of Engineering Pedagogy, 9 (2), 99-116. https://doi.org/10.3991/ ijep.v9i2.9959

[2] Castelan, J. and Bard, R. D. (2018). Promoting PBL through an active learning model and the use of rapid prototyping resources, International Journal of Engineering Pedagogy, 8 (4), 131-142. https://doi.org/10.3991/ijep.v8i4.8281

[3] Taheri, P. (2018). Project-based approach in a first-year engineering course to promote project management and sustainability, International Journal of Engineering Pedagogy, 8 (3), 104-119. https://doi.org/10.3991/ijep.v8i3.8573 
[4] Henning, R. E.and Dunleavy, L. P.(1993). Educating microwave engineers in the United States, IEEE Transactions on Microwave Theory and Techniques, 41 (6), 913-919. https://doi.org/10.1109/22.238504

[5] Hoefer, W. J. (1993). Microwave engineering education in Canada, IEEE Transaction on Microwave Theory and Techniques, 41 (6/7), 932-936. https://doi.org/10.1109/22.238502

[6] Fourikis, N. (1993). Microwave engineering education in Australia, IEEE Transaction on Microwave Theory and Techniques, 41 (6/7), 948-953. https://doi.org/10.1109/22.238508

[7] Eccleston, K. W.(2004). Teaching microwave amplifier design at the undergraduate level, IEEE Transactions on Education, 47 (1), 146-152. https://doi.org/10.1109/te.2003.822635

[8] Bor, S. S., Liu S. J. and Yeh, S. M. (1996). Using feedback techniques to design a stable and matching condition for microwave transistor amplifier, International Journal of Electronics, 81 (6), 713-721. https://doi.org/10.1080/002072196136391

[9] Gonzale, G. (1984). Microwave Transistor amplifiers: analysis and design, Prentice Hall.

[10] Hoefer, W. J. and. So, P. M. (2003). A time-domain virtual electromagnetics laboratory for microwave engineering education, IEEE Transactions on Microwave Theory and Techniques, 51 (4), 1318-1325. https://doi.org/10.1109/tmtt.2003.809189

[11] Trueman, C. W. (2000). Interactive transmission line computer program for undergraduate teaching, IEEE Transactions on Education, 43 (1), 1-14. https://doi.org/10.1109/13.825733

\section{Author}

Abdallah Al-Zoubi received his BSc and $\mathrm{PhD}$ in Electrical and Electronics Engineering from the University of Nottingham, UK, in 1983 and 1987 respectively. He is a senior member of IEEE, ex-Vice President of the International Association of Online Engineering (IAOE), co-founder of the International eLearning Association (IELA), member of the International Mobile Learning Association and Co-Editor of the International Journal of Emerging Technologies in Learning. Al-Zoubi has been a keen advocate for the internationalisation and reform of higher education in Jordan and the Arab world through his position as advisor to the Association of Arab Universities for International Affairs, and has vast experience in EU projects. He has also been involved in numerous exchange projects for staff and students between Europe and Arab universities through Erasmus Mundus and international credit mobility projects. He is actively involved in research in the fields of internationalisation of higher education, engineering education and remote labs, and quality assurance of online learning.

This article is a revised version of a paper presented at the EDUCON2019 conference held in Dubai, UAE, 9-11 April 2019. Article submitted 2019-05-21. Resubmitted 2019-06-02. Final acceptance 2019-0602 . Final version published as submitted by the authors. 